\title{
Distal Anterior Cerebral Artery (Pericallosal Artery) Aneurysms: Report of 19 Cases and Literature Review
}

\author{
Paulo Henrique Pires de AGUIAR¹, Iracema Araújo ESTEVAO², César Cozar PACHECO², \\ Marcos Vinicius Calfat MALDAUN ${ }^{1}$, Carlos Tadeu Parisi de OLIVEIRA ${ }^{3}$ \\ 'Santa Paula Hospital, Department of Neurosurgery, São Paulo - SP, Brazil \\ ${ }^{2}$ São Francisco Hospital School, Department of Neurosurgery, Bragança Paulista - SP, Brazil \\ ${ }^{3}$ São Francisco University, School of Medicine, Bragança Paulista - SP, Brazil
}

\section{ABSTRACT}

AIM: To evaluate the follow-up results of patients who underwent surgical treatment for distal anterior cerebral artery (pericallosal artery) aneurysms and compare our results with the literature.

MATERIAL and METHODS: Nineteen patients were operated between 2000 and 2013 with preoperative angiography and computed tomography (CT) studies. Fisher's classification and World Federation of Neurosurgical Societies (WFNS) subarachnoid hemorrhage (SAH) scale were used to classify the CT findings of the patients. In addition to the clinical and radiological analyses, bibliographical review in indexed databases was also performed.

RESULTS: The female/male ratio was $4: 1$ and the average age was 34 years. The right side was affected in $53 \%$ of cases and $42 \%$ of the aneurysm was ruptured. Distribution of the ruptured aneurysms based on Fisher's classification was as follows: Fisher IV in $25 \%$ of the cases, Fisher III in $37.5 \%$, Fisher II in 12.5\%, and Fisher I in $25 \%$ of the cases. The ruptured aneurysms were Grade I in $50 \%$ of cases, Grade III in $12.5 \%$, and Grade IV in $37.5 \%$ of the cases according to the WFNS grading scale. The average size of the aneurysms was $3.5 \mathrm{~mm}$, and ranged from 3 to $8 \mathrm{~mm}$. One was fusiform and the others were saccular type of aneurysms. The aneurysm was located in fronto-polar artery in $53 \%$ of the cases, while in the callosomarginal artery in $47 \%$ of the cases. Multiple aneurysms were detected in 6 patients. There was no mortality due to surgery.

CONCLUSION: Pericallosal artery aneurysms should have a better prognosis than the aneurysms located in the other parts of the circle of Willis. Complications are related to the patients' age. If possible, these aneurysms should always be clipped due to potential risk of bleeding and difficulty of embolization.

KEYWORDS: Aneurysm, Subarachnoid hemorrhage, Pericallosal artery

\section{INTRODUCTION}

A neurysms of the distal anterior cerebral artery (DACA) are relatively rare, representing 2 to $9 \%$ of all intracranial aneurysms $(3,5,13,14)$. The DACA aneurysms are located in the interhemispheric space, surrounded by the corpus callosum and the cingulate gyrus bilaterally with the interposition of the falx cerebri. Therefore, it is difficult to clip these aneurysms (14).
Technical difficulties for clipping are calcified plaques at the base of aneurysm, narrow surgical corridor in the longitudinal fissure, adhesions in the circulation of the cingulate gyrus and firm adhesions between the two frontal lobes, broadbased aneurysm, presence of azygos of the anterior cerebral artery (ACA), difficulty in establishing the proximal control, aneurysmal sac projection to the surgeon and higher incidence of multiple aneurysms (17). 
DACA aneurysms occur at the origin of callosomarginal artery in $62 \%$ of the cases, at the origin of the frontopolar artery in A2 branch in $20 \%$ of the cases, in the branches of callosomarginal artery in $7 \%$ of the cases, by the paracentral branches in $2 \%$ of cases and in the upper branches of the pericallosal artery in $9 \%$ of cases $(3,5,13,17)$. The $A 3$ aneurysms are rare, and constitute $5 \%$ of all aneurysms of the ACA (15). The aneurysms of A4 and A5 segments are more frequent than the A3 (16).

Patients with such aneurysms may present with sudden headache followed by meningeal irritation syndrome. Computed tomography (CT) scan usually shows haematoma in the longitudinal fissure, above the corpus callosum, in the frontal lobe and/or cingulate gyrus. There may often be ventricular hemorrhage. A greater number of incidental aneurysms is detected in magnetic resonance imaging (MRI) of the patients.

Due to the factors mentioned above, pericallosal aneurysms are generally considered difficult to treat with a worse prognosis compared to others aneurysms of the anterior part of the circle of Willis $(2,32)$. Other studies showed that morbidity of DACA aneurysms is not greater than the aneurysms of other locations $(5,6,9,20,34)$.

In this study, we analyzed the clinical features and the treatment of 19 patients who had DACA aneurysms and were treated by the same group of surgeons. Our aim was to evaluate the follow-up results of these patients and compare our findings with the literature.

\section{- MATERIAL and METHODS}

During the period 2000-2013, the first author operated 19 cases of aneurysms located at the distal portion of the ACA. The surgical interventions were performed at the Santa Paula Hospital. Complete medical records, including clinical presentation, physical examination at admission, results of the CT scan and angiography, preoperative clinical status, surgical approach and last ambulatory control, were obtained for all patients. We used the Fisher classification and the World Federation of Neurosurgical Societies (WFNS) subarachnoid hemorrhage (SAH) grading scale to classify the CT findings of the patients. In addition, bibliographical analysis in indexed databases was performed.

\section{- RESULTS}

Of the 19 patients, 15 were women and 4 men. The female/ male ratio was $4: 1$. The age of the patients ranged between 19 and 76 years, and the mean age was 34 years.

Among the medical history of 19 patients, 16 cases had hypertension, 4 were overweight, 3 had obesity, 4 had diabetes mellitus or pre-diabetic condition, 1 had multiple sclerosis, 1 had lupus, 1 had polycystic kidney disease, 2 had renal cysts, 1 had Ehlers-Danlos syndrome, 1 had repeated transient ischemic attack and 1 had schizophrenia. Eight patients were smokers and 3 patients had a family history of cerebrovascular disease.
Eleven aneurysms were incidentally diagnosed during radiological examinations for chronic headache. The most common symptom was thunderclap headache, which is characteristic for SAH. Less frequent symptoms were motor deficits, seizures and transient loss of consciousness. Three patients had a family history of cerebrovascular disease. Two patients had motor deficits. One of them had with right hemiparesis after SAH and another had double hemiparesis of crural predominance. Physical examination showed nuchal rigidity in $4(21 \%)$ patients. One patient had normal physical examination after a generalized tonic-clonic seizure and one patient fell into coma abruptly.

Eight patients (42\%) had ruptured aneurysms. Based on CT examination, the Fisher grade was IV in $2(25 \%)$ cases, III in 3 $(37.5 \%)$ cases, II in 1 (12.5) case and I in $2(25 \%)$ cases. WFNS SAH Grade (30) was I in 4 (50\%) cases, III in 1 (12.5\%) case, and IV in $3(37.5 \%)$ cases.

The average size of the aneurysms was $3.5 \mathrm{~mm}$, ranging from 3 to $8 \mathrm{~mm}$. One was fusiform and others were saccular type of aneurysms. Fifty-three percent of the aneurysms were located in fronto-polar artery and $47 \%$ of them were located in callosomarginal artery. Six cases had multiple aneurysms.

Overall mortality was $10.5 \%$ (2 cases). There was no mortality directly related to surgery. One patient with unruptured aneurysm died due to mesenteric thrombosis two months after the surgery and another patient died because of vasospasm and bilateral ischemia after 45 days of hospitalization. Seventeen $89.5 \%$ ) patients had an excellent or good outcome.

\section{DISCUSSION}

ACA is the front end branch of the internal carotid artery (11, $19,22,27)$. It arises in the inner sector of the Sylvian fissure, lateral to the optic chiasm and below the anterior perforated substance. It travels up, anteriorly and medially above the optic nerve $(30 \%)$ or optic chiasm $(70 \%)$ and below the medial striatum olfactory to enter the longitudinal fissure (19).

Before entering the interhemispheric fissure, it makes anastomoses with its opposite counterpart through the anterior communicating artery and ascends to the front of the lamina terminalis until it reaches the longitudinal fissure between the hemispheres. Above the lamina terminalis, the arteries form a curve around the knee of corpus callosum, assuming posterior direction in the pericallosal cistern and then bend out of the corpus callosum, delineating its boundary and ends at the choroid plexus of the floor of third ventricle $(11,22,27)$. Figure 1 shows an anatomical piece concerning the anterior interhemispheric arteries and structures of the brain. In this section, five segments are identified: A1-pre-communicating; A2-infracallosal; A3-pre-callosal; A4-supracallosal; A5-postcallosal/splenial segments. The distal ACA corresponds to the segments A2-A5 (19).

Some authors consider the pericallosal artery (PCA) as a branch that arises immediately at the origin of the callosomarginal artery (CMA) from ACA (19). Given the variability in the morphology, topography and size of this bifurcation, these 


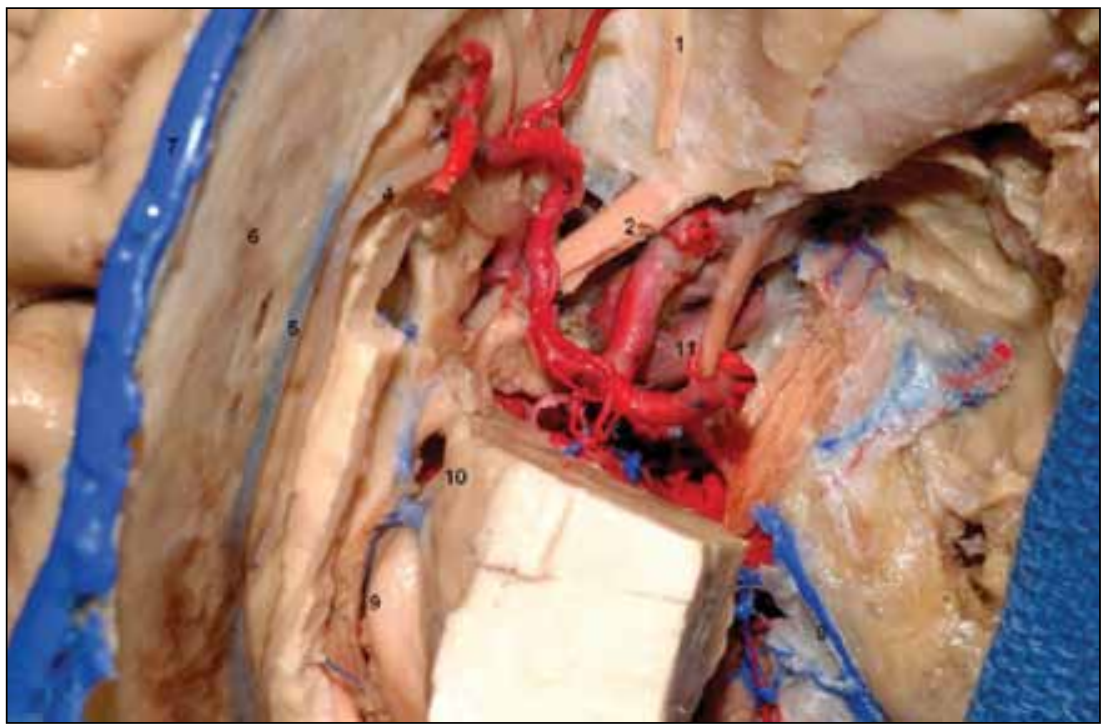

Figure 1: Anatomical piece-Lateral view of the left cerebral hemisphere (author Gustavo Isolan). The frontal lobe and part of the temporal and parietal lobes were resected to expose the path of the pericallosal artery. 1. Olfactory nerve; 2. Optic nerve; 3. Anterior cerebral artery; 4. Callosomarginal artery; 5 . Inferior sagittal sinus; 6 . Falx cerebri 7. Superior sagittal sinus 8. Sphenoparietal sinus 9. Cingulate gyrus 10. Corpus callosum 11. Internal carotid artery.

authors stated that the ACA, from the anterior communicating artery, should be called as "pericallosal artery" (22). The callosomarginal artery could be a branch of pericallosal artery. The point of origin and caliber of this artery are variable.

The PCA gives various cortical branches such as orbitofrontal arteries, fronto-polar, callosomarginal, anterior internal frontal, middle and posterior, superior and inferior parietal and paracentral arteries. Therefore, the presence of thick callosomarginal artery may be confused with PCA (27). Likewise, some of the frontal arteries can lead to the callosomarginal artery.

PCA feeds the corpus callosum and gives small basal perforating branches to the hypothalamus, septum pellucidum, fornix, white anterior commissure and anterior portion of the striatum (11). In more than $70 \%$ of cases, the Heubner artery arises from the $\mathrm{A} 2$ sector, at the communicating artery level (22). Through its branches, the PCA feeds the majority of the internal face of the cerebral hemispheres, the inner half of the basal face of the frontal lobe, the outer face of the first frontal gyrus (F1) and the upper portion of the pre- and postcentral areas (27). It also covers the vasculature to the corpus callosum and one PCA gives branches to the contralateral hemisphere in $2 / 3$ of the cases (22).

Major variations of the PCA are the median artery of the corpus callosum, the azygos ACA and bihemispheric pericallosal artery $(1,22)$. These variations are seen in more than $10 \%$ of cases (17). In the presence of bihemispheric pericallosal artery, one of the pericallosal arteries has an important role on the vascularization of contralateral hemisphere (1). The aneurysms of PCA may be located at the origin of its cortical branches. However, these aneurysms are mostly seen at the greater arterial bifurcations such as pericallosal and callosomarginal artery bifurcations. The infracallosal aneurysms are more complex (4).

The ages of the patients vary from 40.6 to 54 years in most of the publications $(3-5,8,10,13,29,31)$. In our study, the ages of the patients were between 19 and 76 years with a mean age of 34 years and this result is similar with the literature $(3-5,8$, $10,13,29,31)$. In our patient population, the female/male ratio was $4: 1$ and a female predominance is seen in the majority of the publications in varying proportions as $1.2: 1$ to $2: 1(2,12)$. A male predominance was reported in the series of Laitinen (13) Yasargil (12), and Hernesniemi (8).

In our series, based on their personal history, 16 patients had hypertension, 8 patients were smokers, 4 patients were overweight, and 3 patients were obese. In the literature, hypertension is the most important factor among the patients with a DACA aneurysm $(2,25)$. In our series, 3 patients had a family history of cerebrovascular disease.

The typical clinical symptom of $\mathrm{SAH}$ is severe headache, which is different than any other that patients have felt before, and was present in 11 of 19 cases in our series. The intense headache was also reported by other authors in $50 \%$ to $100 \%$ of their cases (5). Other signs and symptoms were nausea, vomiting, neck stiffness and loss of consciousness, which are similar with the literature (26). Generalized seizures are infrequent and were reported from $0 \%$ to $6.9 \%$ in the previous series $(5,6,10)$. In our series, one patient had generalized seizures. Other symptoms are: lower-extremity paraparesis or monoparesis, hemiparesis, and hypoesthesia due to compromised paracentral lobe. Exceptionally there may be sphincter incontinence or behavioral disorders due to dysfunction of the frontal lobe, and transient aphasia by decreasing the flow in the left PCA $(2,4,13,23)$.

Computed tomography showed blood in the cisterns in 8 of 19 cases as seen in Figure 2. Fisher (7) stated that the distribution of bleeding may give information about the topography of aneurysms in most of the patients. For example, the presence of blood in the anterior part of the pericallosal cistern and hematoma in the corpus callosum may be suggestive for a bleeding of the PCA aneurysm. In our series, 2 cases $(25 \%)$ had Fisher IV, 3 cases (37.5\%) had Fisher III, 1 case (12.5\%) had Fisher II and 2 cases (25\%) had Fisher I SAH based on 
CT examinations. According to WFNS SAH grading scale (30), $50 \%$ (4 cases) had Grade I, $12.5 \%$ (1 case) had Grade III and $37.5 \%$ ( 3 cases) had Grade IV SAH.

Most aneurysms of DACA arise at the origin of callosomarginal artery (Figure 2) $(2,12,29)$. The other locations are as follows: 1) near the origin of the fronto-polar or orbitofrontal arteries; 2 ) distal part of the pericallosal artery and 3) peripheral branches

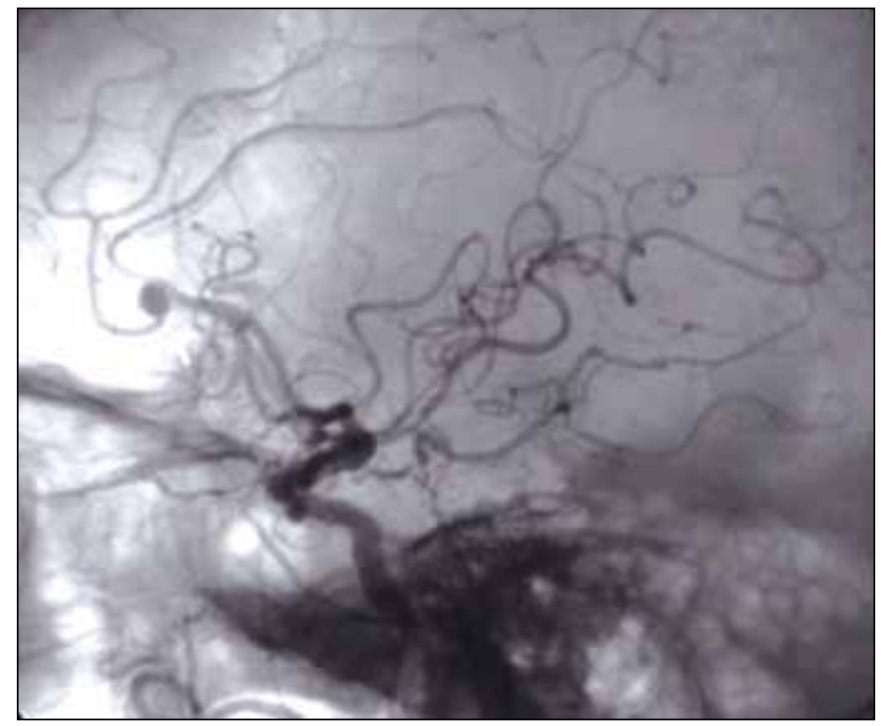

Figure 2: Cerebral angiography showing a saccular aneurysm at the pericallosal artery (white arrow). of the callosomarginal artery or pericallosal artery $(12,32-$ 34). These locations are less frequent than the origin of the callosomarginal artery.

Surgically, the PCA aneurysms are classified based on 3 criteria such as origin of the aneurysm, relationship with the corpus callosum and surgical approach (18). According to corpus callosum, the aneurysms may be located infracallosal, at the knee of the corpus callosum or supracallosal. They can also be divided into two groups as aneurysms of the ascending portion of PCA $(33,34)$ and aneurysms of the horizontal portion of PCA. Both groups have different surgical approaches.

Reports on giant aneurysms of the PCA are limited (20). This may be due to bleeding tendency of these aneurysms, even when they are small (23). The basal interhemispheric approach is preferred by many authors as it allows accessing the PCA quickly and provides easy proximal control of the aneurysm $(5,27,33)$.

Yoshimoto et al. $(33,34)$ reported two different surgical approaches according to the location of the aneurysm. Bicoronal approach using a craniotomy with bifrontal section of the sagittal sinus is suitable for the aneurysms located in the ascending portion of PCA (between the anterior communicating artery and the knee of the corpus callosum). Then, the aneurysm is dissected from the carotid bifurcation in order to have proximal control (Figure 3). De Souza et al. (5) used similar approach with a small unilateral rightside craniotomy and with the preservation of the sagittal sinus (Figure 4). It is difficult to perform this approach in the presence of frontal bridging vein because injury of this vein

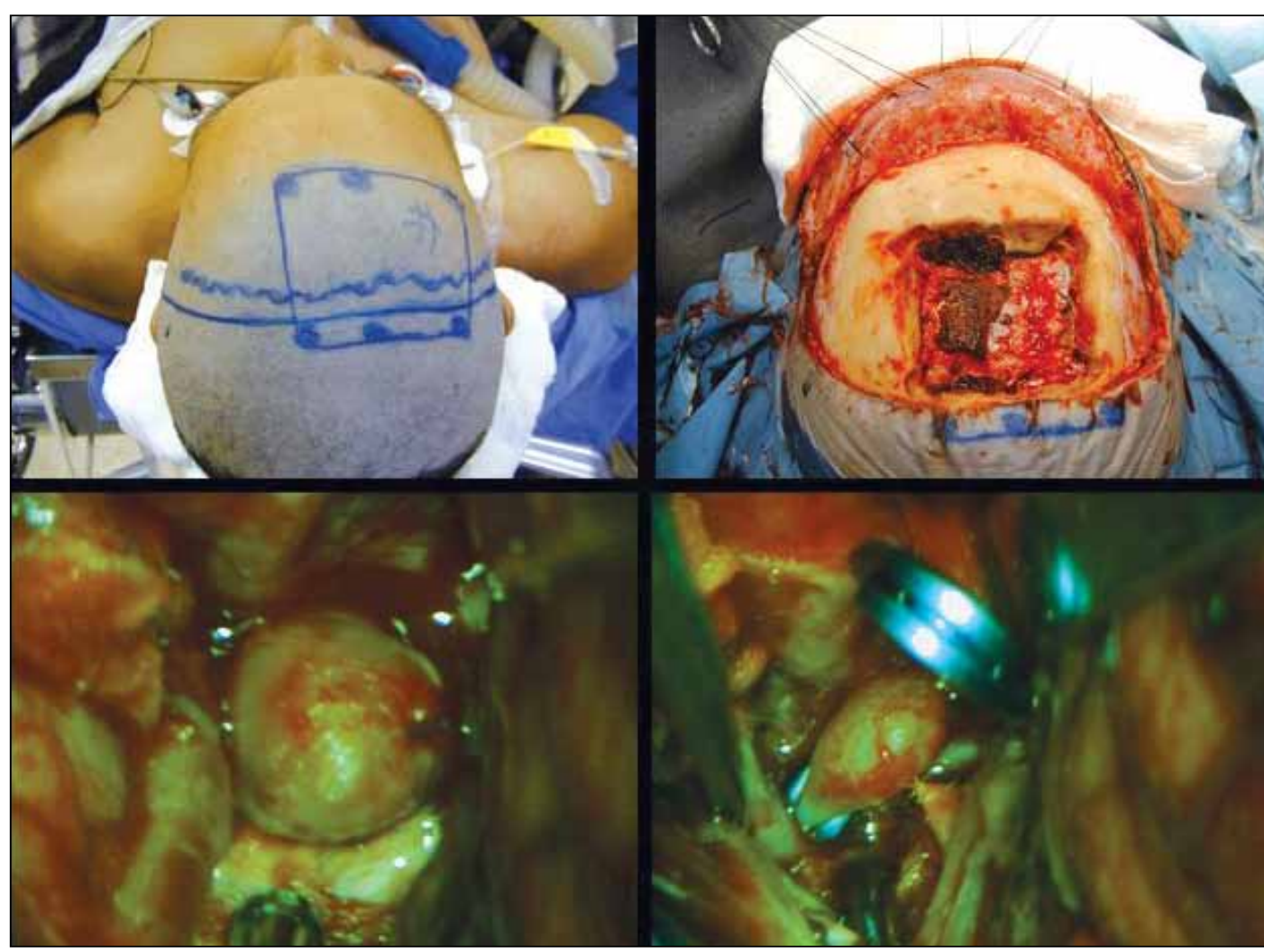

Figure 3: Bicoronal incision marked to access the frontal pole and the points for craniotomy. Microsurgical exposure of the aneurysm in microscopic view and clipping of the aneurysm with semi-curved clip. 
may result in venous infarction, may increase brain swelling, and complicate the surgical approach. Sugita et al. (28) and Sampei et al. (23) reported that patients with sacrificed frontal veins in an interhemispheric approach have three times more risk for frontal ischemic complications when compared to those with preservation of the veins.

Some authors $(8,21)$ routinely use pterional approach for lowlying PCA aneurysms. They think that the small enlargement of the skin incision and bone flap may provide better access to the multiple aneurysms during the same surgical procedure. In our series, no patient with multiple aneurysms was operated during the same session.

The aneurysms of the horizontal portion of PCA can be operated by a horseshoe skin incision, centered on the topography of the aneurysm. The bone flap can be triangular $(5,10)$ or square type $(8,10,18,20)$ according to the surgeon's preference. However, the base of the bone flap should be at least above the sinus. Through this approach, we can reach directly the distal part of the aneurysm and this increases the potential risk of rupture during the dissection of aneurysm.

The section of the knee of corpus callosum can be useful for the proximal control of the PCA (6). In some cases, it may be important to dissect the anterior part of the interhemispheric cistern, and to move distally to take control of the afferent vessel (5). It is also important to distinguish the corpus callosum and the cingulate gyrus during the interhemispheric approach. Corpus callosum has an intense white color when compared with the cingulate gyrus (10).

Yasargil (32) reported that the intraoperative rupture of PCA aneurysms was frequent. This may be due to the adherence of the aneurysmal sac to the cingulate gyrus. Therefore, the surgeon first reaches to the fundus of the aneurysm instead of its base. However, other authors, who have investigated the causes of early intraoperative rupture of the aneurysms, have not found a significant difference between PCA aneurysms and other aneurysms (9). Traynelis and Duncan reported less risk of premature rupture of the aneurysm for the transcallosal approach to the infracallosal aneurysms despite their greater complexity (31). In our study, there was no intraoperative rupture before the clipping of aneurysm. This influenced the postoperative clinical outcome of the patients.

In our study, the overall mortality was $10.5 \%$ ( 2 cases). There was no mortality related to surgery itself, but one patient with unruptured aneurysm died due to mesenteric thrombosis two months after the surgery and another patient died because of vasospasm and bilateral ischemia after 45 days of hospitalization. Of the 19 patients, 17 had an excellent or good outcome. Excellent or good results were reported between $50.4 \%$ and $90.6 \%$ of cases in the literature $(14,23$, 29). Lee et al. reported poor results in 126 patients with DACA aneurysms and the mortality rate was $0.9 \%(14)$. Among the postoperative sequelae, the neuropsychiatric disorders were more common in aneurysms of the anterior communicating artery complex and accounted for about $10 \%$ of cases (14). Clinical results of ruptured aneurysms were worse than non-ruptured aneurysms because of the hydrocephalus, vasospasm and electrolyte disturbances associated with intracranial hypertension (3).

Our results were similar to the series of other authors who have reported good results in surgeries of DACA aneurysms. For example, Yoshimoto et al. (33) and Takaku et al. (29) had an overall mortality of $6.1 \%$. The lowest mortality was found in the PCA aneurysms as $4.1 \%$. The highest mortality for PCA aneurysms was $15 \%(17,23)$. Yasargil $(32)$ reported technical difficulties of PCA aneurysms, but the mortality was $0 \%$ in his series of PCA aneurysms (32).

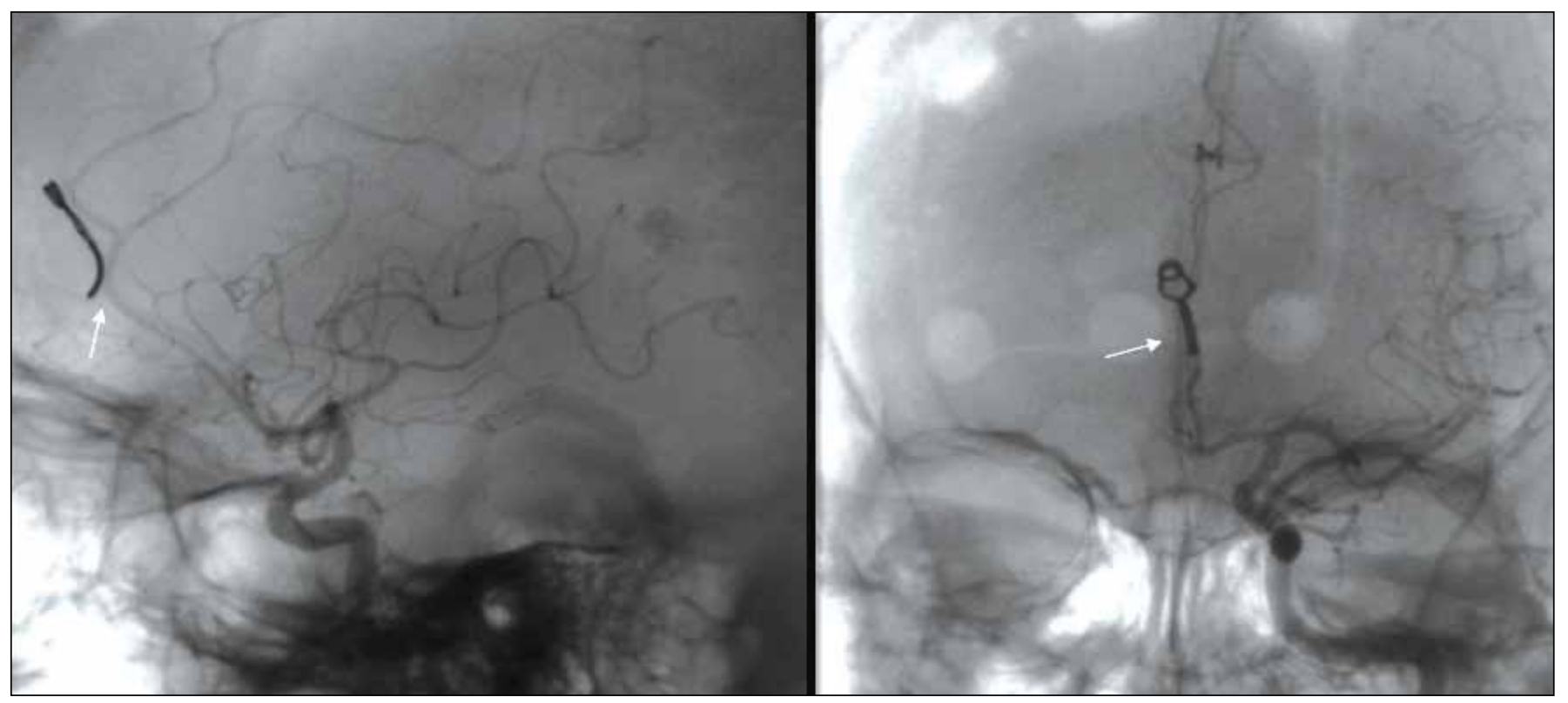

Figure 4: Angiography effectively shows pericallosal aneurysm clipping using a Sugita titanium semi-curved clip (white arrow). 
The multiple aneurysms involving the DACA should be treated by two approaches at different times. Bleeding on the cingulate gyrus may lead to mutism syndrome (24). The venous infarction can be seen after the section of bridging veins in the frontal lobe. The pericallosal arteries are narrow and it is difficult to apply the clips leading to significant stenosis and occlusions of the vessel.

\section{CONCLUSION}

Pericallosal artery aneurysms should have good prognosis when compared to other locations in the anterior portion of the circle of Willis. Complications are related to the patient's age and the lesions should, where possible, be clipped due to the potential risk of bleeding and difficulty of embolization.

\section{- REFERENCES}

1. Baptista AG: Studies of the arteries of the brain II. The anterior cerebral artery: Some anatomical features and their clinical implications. Neurology 13: 825-835, 1963

2. Becker $\mathrm{DH}$, Newton TH: Distal anterior cerebral artery aneurysm. Neurosurgery 4: 495-503, 1979

3. Colli BO, Carlotti Jr CG: Aneurismas da artéria cerebral anterior distal (aneurismas da artéria pericalosa). In: Tedeschi $\mathrm{H}$, Pereira CU (eds). Doenças Cérebro Vasculares. Diagnóstico e Tratamento. Capítulo 8. Rio de Janeiro: Revinter, 2004: 8591 (In Portugese)

4. Critchley M: The anterior cerebral artery, and its syndromes. Brain 53:120-165, 1930

5. De Souza AA, Dantas FLR, De Cardoso GTC, Costa BS: Distal anterior cerebral artery aneurysms. Surg Neurol 52:128-136, 1999

6. Dickey PS, Bioomgarden GM, Arkins TJ, Spencer DD: Partial callosal resection for pericallosal aneurysms. Neurosurgery 30: 136-137, 1999

7. Fisher RG, Ciminelo V: Pericallosal aneurysms. J Neurosurg 25: 512- 515, 1996

8. Hernesniemi J, Tapaninaho A, Vapalathi M, Niskanen M, Kari A, Luukkonen M: Saccular aneurysm of the distal anterior cerebral artery and its branches. Neurosurgery 31: 994-995, 1992

9. Houkin K, Kuroda S, Takahashi A, Takikawa S, Ishikawa T, Yoshimoto $\mathrm{Y}$, Itamato $\mathrm{K}$ : Intra-operative premature rupture of the cerebral aneurysms. Analysis of the causes and management. Acta Neurochir (Wien) 141:1255-1263, 1999

10. Inci S, Erbengi A, Ozgen T: Aneurysm of the distal anterior cerebral artery: Report of 14 cases and a review of the literature. Surg Neurol 50: 130-140, 1998

11. Kakou M, Destrieux C, Velut S: Microanatomy of the pericallosal arterial complex. J Neurosurg 93: 667-675, 2000

12. Krayenbuhl H, Yasargil MG: Cerebral angiography. London: Butterworths, 1968

13. Laintinen L, Snellman A: Aneurysms of the pericallosal artery: A study of 14 cases verified angiographically and treated mainly by direct surgical attack. J Neurosurg 17:447-458, 1960
14. Lee JW, Lee KC, Kim YB, Huh SK: Surgery for distal anterior cerebral artery aneurysms. Surg Neurol 70: 153-159, 2008

15. Lehecka M, Dasthi R, Hernesniemi J, Nemel A, Kolvisto T, Ronkainen A, Rinne J, Jaaskelainen J: Microneurosurgical management of aneurysm at A3 segment of anterior cerebral artery. Surg Neurol 70:135-151, 2008

16. Lehecka M, Dasthi R, Hernesniemi J, Nemel A, Kolvisto T, Ronkainen A, Rinne J, Jaaskelainen J: Microneurosurgical management of aneurysm at A4 and A5 segments and distal cortical branches of anterior cerebral artery. Surg Neurol 70: 352-367, 2008

17. Martínez F, Spagnuolo E, Calvo A, Laza S, Sgarbi N, Soria $\mathrm{V}$, Prinzo $\mathrm{H}$ : Variaciones del sector anterior del polígono de Willis. Correlación anatomo-angiográfica y su implicancia quirúrgica. (arterias: ácigos cerebral anterior, mediana del cuerpo calloso y cerebral media accesoria). Neurocirugía 15: 578-588, 2004 (in Spanish)

18. Ohno K, Monma S, Suzuki R, Matsushima, Y, Hirakawa K: Saccular aneurysm of the distal anterior cerebral artery. Neurosurgery 27: 907-913, 1990

19. Perlmutter D, Rhoton AL, Jr: Microsurgical anatomy of the distal anterior cerebral artery. J Neurosurg 49: 204-228, 1978

20. Preul M, Tampieri D, Leblanc R: Giant aneurysm of the distal anterior cerebral artery: Associate with an anterior communicating artery aneurysm and a dural arteriovenous fistula. Surg Neurol 38: 347-352, 1992

21. Proust F, Toussaint $P$, Hannequin D, Rabenenoina $C$, Le Gars D, Fréger P: Outcome in 43 patients with distal anterior cerebral artery aneurysms. Stroke 28: 2405-2409, 1997

22. Rhoton AL Jr: Aneurysms. Neurosurgery 51 Suppl 1: S121-S158, 2002

23. Sampei T, Yasui N, Okudera T, Fukasawa H: Anatomic study of anterior frontal cortical veins with special reference to the frontopolar vein. Neurosurgery 38: 971-975, 1996

24. Shucart WA, Heilman CB: Surgical management of anterior cerebral artery aneurysm distal to communicating artery. In: Schmidek HH (ed). Operative Neurosurgical Techniques. Vol 1, $3^{\text {rd }}$ ed. Philadelphia: WB Saunders, 1995: 1035-1039

25. Spagnuolo E, Johnston E, Tarigo A, Calvo A: Factores que inciden em el pronóstico de los pacientes con hemorragia subaracnoidea por aneurisma. Rev Hosp Maciel 25:15-22, 1995 (in Spanish)

26. Solomon RA: Surgical treatment of anterior circulation aneurysms. In: Awad I (ed). Current Management of Cerebral Aneurysms. AANS, 1993: 125-158

27. Stefani MA, Marrrone ACH, Severino AG, Schneider FL: Importância clínica e cirúrgica dos ramos distais da artéria cerebral anterior. J Bras Neurocirurg 8:41-50,1997 (in Portugese)

28. Sugita K, Kobayashi S, Yokoo A: Preservation of large bridging veins during brain retraction. Technical note. J Neurosurg 57: 856-858, 1982

29. Takaku A, Tanaka S, Mori T, Suzuki J: Postoperative complications in 1000 cases of intracranial aneurysms. In: Suzuki J (ed). Cerebral Aneurysms. Experiences with 1000 Directly Operated Cases. Tokyo: Neuron Publishing Co, 1979: 633-643 
30. Teasdale GM, Drake CG, Hunt W, Kassell N, Sano K, Pertuiset B, De Villiers JC: A universal subarachnoid hemorrhage scale: Report of a committee of the World Federation of Neurosurgical Societies. J Neurol Neurosurg Psychiatry 51(11): 1457, 1988

31. Traynelis VC, Dunker RO: Interhemispheric approach with callosal resection for distal anterior cerebral artery aneurysms. Technical note. J Neurosurg 77: 481-483, 1992

32. Yasargil MG: Microneurosurgery: Microsurgical anatomy of the basal cistems and vessels of the brain, diagnosis studies, general operative techniques and pathological considerations of the intracranial aneurysms. Stuttgart: George Thieme Verlag, 1984
33. Yoshimoto T, Uchida K, Kaneko U, Kayama T, Suzuki J: An analysis of follow-up results of 1000 intracranial saccular aneurysms with definitive surgical treatment. J Neurosurg 50: 152-157, 1979

34. Yoshimoto T, Uchida K, Suzuki J: Surgical treatment of distal anterior cerebral artery aneurysms. In: Suzuki J (ed), Cerebral Aneurysms. Experiences with 1000 Directly Operated Cases. Tokyo: Neuron Publishing Co, 1979: 250-255 